\title{
Psychological Distress Among Non-Human Animal Rescue Workers: An Exploratory Study
}

\author{
Raegan Murphy \\ School of Applied Psychology, University College Cork, Ireland \\ raegan.murphy@ucc.ie \\ Shaunagh Louise Daly \\ School of Applied Psychology, University College Cork, Ireland
}

\begin{abstract}
To better understand the psychological effects on humans of working with distressed non-human animals, I set out to understand the professional quality of life experienced by this group of workers. Measures included compassion satisfaction, burnout, and secondary traumatic stress. An online survey-based cross-sectional correlational design was employed to survey 340 animal rescue workers. The survey consisted of items assessing demographic information (gender, age, geographic location), type of work performed (single or multiple caring roles), exposure to euthanasia, in-home fostering of animals, and whether the work was salaried or voluntary. The results of the present study may prove useful for both animal rescue organizations and animal rescue workers who may be experiencing distress as a result of their work. Recommendations for future research include a focus on the effects of exposure to euthanasia and the home fostering of rescue animals.
\end{abstract}

\section{Keywords}

non-human animal rescue workers - compassion satisfaction - burnout - secondary traumatic stress - Professional Quality of Life Scale (ProQOL) 


\section{Introduction}

Stories of non-human animal abuse and neglect are common across worldwide media today. What is typically distressing for an individual to view on social media or in the newspaper is something that animal rescue workers are exposed to on a regular basis. Many take on such work with the hope of saving lives, but often instead find themselves filled with anguish and guilt. For example, shelter workers may find themselves involved in the euthanasia of animals for whom no space or home can be found. Foster carers may ultimately fail to rehabilitate an animal that has been exposed to severe cruelty, and these carers may suffer psychological distress.

Those working or volunteering within animal rescue most typically take on such work due to a deep-seated passion for the care and protection of animals and as a consequence are paradoxically exposed to the horrific abuse and cruelty of those same animals on a recurring basis. While the heartfelt connection with animals is clearly evident in their work, what causes an animal rescue worker to experience immense joy and satisfaction is also very often the same thing that leads to the development of work-related psychological experiences such as lowered compassion satisfaction, increased burnout, and increased secondary traumatic stress.

Animal rescue workers remain under-researched across the psychological literature, and a small number of researchers have acknowledged a particular sub-group - those working in shelters and participating in euthanasia-as being particularly vulnerable to lower levels of work satisfaction (Schneider \& Roberts, 2016). Schneider and Roberts identified several unique occupational stressors among animal shelter workers which would not typically be seen across generic descriptors of occupational stress such as the guilt experienced taking vacation leave. Their qualitative study revealed rich data on a small sample of animal care workers.

A study on euthanasia-related strain in animal shelter employees showed that euthanizing animals is a major stressor for many of them (Baran et al., 2009). Euthanasia technicians frequently experience guilt, grief, and frustration as a result of their role in animal rescue (Arluke \& Sanders, 1996; Frommer \& Arluke, 1999). Euthanasia exposure has been associated with higher levels of substance abuse, somatic complaints such as headaches and loss of appetite, conflict with family members, and a lower degree of job satisfaction, than in animal shelter employees not involved in euthanasia practices (Reeve et al., 2005).

Qualitative studies have similar findings with regard to the negative consequences of euthanasia-related stress (Arluke \& Sanders, 1996; Frommer \& 
Arluke, 1999). Similarly, veterinarians facing the euthanasia of companion animals of whom they have become fond and to whom they have become attached may suffer from emotional ambivalence and experience conflicting feelings (Arluke, 1991). Euthanasia has been identified as a source of occupational stress for veterinarians in a number of other studies (Sanders, 1995; Schneider, 1996).

The Professional Quality of Life Scale (ProQOL; Stamm, 2010) was used in this study as a reliable and validated measure of the experiences within working environments. Three subscales were used to measure compassion satisfaction, burnout, and secondary traumatic stress exposure. Compassion satisfaction refers to how satisfied and successful professionals are within their working roles and how their caregiving results in feelings of gratification (Conrad \& Kellar-Guenther, 2006; Simon et al., 2006). An individual experiencing compassion satisfaction derives pleasure from the act of helping, enjoys making contributions, and feels good about their ability to help (Stamm, 2002).

Burnout is defined as a toxic mix of emotional exhaustion, depersonalization, and feelings of reduced personal accomplishment within the working environment (Maslach \& Jackson, 1986). While the term burnout was originally conceptualized to describe the negative effects of "people work," it has been augmented to encompass the negative effects of all occupations (Leiter \& Schaufeli, 1996). Burnout is characterized by a number of easily recognizable physiological, emotional, behavioral, and cognitive indicators (Aguilera, 1995). Physiological reactions include headaches, exhaustion, and hypertension, while emotional responses to burnout include emotional exhaustion, emotional numbing, anxiety, and depression (Figley \& Roop, 2006).

Behavioral indicators include a decline in performance, interpersonal difficulties, increased dependencies, and insomnia (NiCarthy, Merriam, \& Coffman, 1984), with cognitive symptoms including self-blame, self-doubt, and general disillusionment (Prosser et al., 1996). Burnout is also characterized by a loss of motivation to work within the current role and usually occurs over a longer period of time (Cherniss, 1980; Farber, 1983). Animal rescue workers have considerable work hours, particularly those who provide round-the-clock foster care for rescue animals in their homes. It is conceivable that animal rescue workers may be particularly vulnerable to burnout due to possible work overload.

Figley (1995) states that secondary traumatic stress can be described as "the stress resulting from helping or wanting to help a traumatized or suffering individual" (p. 7). Those experiencing adverse symptoms as a direct result of trauma are known as primary trauma survivors. However, the caregivers of such individuals, who are indirectly exposed to the trauma of the survivor, can 
themselves become affected by secondary trauma. Such caregivers, in their attempt to help a survivor of primary trauma - a pertinent example is a dog rescued from a dog-fighting ring — can experience similar symptoms to those that the primary trauma survivor experiences.

Like burnout, secondary traumatic stress causes a variety of cognitive, emotional, behavioral, and physical symptoms. These include intrusive thoughts, feelings of detachment from others, nightmares, sleep disturbances, and hypervigilance (Barnes, 2004), along with dizziness, breathing difficulties, guilt, confusion, high startle response, and many more (Figley \& Roop, 2006). In contrast to burnout, secondary traumatic stress symptoms are generally rapid in onset and associated with a specific event (Tiplady, 2013).

To date, there has been little research on the prevalence of compassion satisfaction, burnout, and secondary traumatic stress in animal rescue workers. As a result, the following study was designed to explore the prevalence of these phenomena in this under-researched and vulnerable population.

\section{Materials and Methods}

An online survey using a cross-sectional correlational design was employed to survey animal rescue workers; the sample size was 340. Participants were recruited through online contact via social media and email with several animal rescue/welfare organizations. Responding organizations in turn disseminated the questionnaire link to their staff and volunteers to complete if they wanted to participate. On clicking the survey link, participants were provided with a webpage to read before beginning. The webpage contained general information on the purpose of the study, the anonymous nature of participation, and how the data would be stored after collection. Participants were informed that they could exit the survey at any point and that their responses would not be stored with completed responses. Lastly, participants were given the contact details of the researchers if they changed their minds and wished for their records to be removed from the data set.

\section{Ethics}

Prior to participating in the study, individuals were required to read and agree to participation. Ethical oversight and approval for this study was provided by the Ethics Committee of the School of Applied Psychology at University College Cork. This research was carried out in accordance with the Psychological Society of Ireland's Code of Professional Ethics (https://www.psychologicalso -ciety.ie/footer/PSI-Code-of-Professional-Ethics-3). 


\section{Materials}

The first section of the survey questionnaire contained several sociodemographic and work-related items on gender; age; type of work (salaried or volunteer); type of role performed within the rescue organization such as fostering, sheltering, or administrative; whether any rescued animals were being looked after at the participants' homes, and if so, the number of those animals. The latter three items were included in the questionnaire in line with previous research on the effects of role/work overload and exposure to traumatized individuals - in this case, animals - on caregivers, to explore possible similarities among animal rescue workers (e.g., Barr, 2017; de Beer et al., 2016; Ewer et al., 2015; Killian, 2008; Outar \& Rose, 2017).

Additionally, as per previous research on euthanasia and animal care professions (Baran et al., 2009; Reeve et al., 2005), respondents were asked if they were exposed to the euthanasia of animals through their rescue work. The second and final section of the survey included ProQOL Version 5 (Stamm, 2010). ProQOL has been both a reliable and valid tool in a variety of contexts (Lauvrud, Nonstad, \& Palmstierna, 2009; Luster, 2005). While ProQOL was initially developed for emergency staff and trauma counselors, the scale is now used internationally as a psychometrically validated tool in a diverse range of target populations.

The scale is composed of thirty, five-point Likert-type items (ranging from one $=$ never, to five $=$ very often). The 10-item subscales measure three separate constructs: compassion satisfaction (alpha scale reliability: .88), burnout (alpha scale reliability: .75 ), and secondary traumatic stress (alpha scale reliability: .81) (Stamm, 2010). The terminology used in the ProQOL scale was adapted for use with animal rescue workers in the present study. For example, item two on the scale I am preoccupied with more than one person I help was changed to I am preoccupied with more than one animal I help, while item 13 was changed from I feel depressed because of the traumatic experiences of the people I help to I feel depressed because of the traumatic experiences of the animals I help, and so on. The basis for these required changes is an earlier study of animal care professionals in which ProQOL was employed to evaluate the effectiveness of a training-as-treatment intervention (Rank, Zaparanick, \& Gentry, 2009).

\section{Data Analysis}

Data were analyzed using spss Version 24.0, and as the data were nominal and ordinal, categorical-specific analyses were used unless summated ratio scales were analyzed. When the scales were analyzed, case parametric tests were used. A total of 481 participants started filling out the survey, but only 340 
completed all sections. The researchers conducted all analyses on a realized sample of 340 respondents. Participants' raw scores were calculated for each subscale, and all reverse-scored items were correctly entered. Next, raw scores on each subscale were transformed into $Z$ - and $T$-scores with a mean of 50 and standard deviation of 10, in accordance with the ProQOL (2010) manual.

While the manual indicates that the ProQOL measure is best used in its continuous form, cut-scores are provided for each scale for use in research investigating relative risk or protective factors such as in the present study. Pearson correlations and partial correlations were conducted to investigate potential relationships between compassion satisfaction, burnout, and secondary traumatic stress scores. Mann-Whitney $U$ tests were conducted to examine potential group differences within each of the six sociodemographic and work variables, and participants' scores on compassion satisfaction, burnout, and secondary traumatic stress. Next, $\chi^{2}$ tests of independence were performed to examine the likelihood of responses across participants on each of the three subscales. In the final stage of the analysis, binary logistic regression was conducted to examine probabilistic relationships in the data. A significance level of $5 \%$ was adopted for all analyses.

\section{Results}

The six dichotomous variables included in the analyses comprise gender (male/female), age (younger: $<56$, older: $56+$ ), nature of work (paid/voluntary), number of roles carried out (caring for single/multiple animals), whether animals are cared for in the home (no/yes), and exposure to euthanasia as part of the work (no/yes). The only variable which was collapsed was the age variable due to the younger age skew of distribution. Table 1 illustrates the sample characteristics used in this study.

\section{Compassion Satisfaction, Burnout, and Secondary Traumatic Stress Associations}

The three ProQOL subscales accounted for independent variance in the total questionnaire and hence measured separate constructs (Stamm, 2010). However, directional relationships were expected (Table 2). Pearson bivariate correlations were all statistically significant. When the relationships were controlled for, the only coefficient that became statistically non-significant and changed direction was the correlation between compassion satisfaction and secondary traumatic stress after burnout. 
TABLE 1 Sample and work characteristics

\begin{tabular}{|c|c|c|}
\hline Variable & & $N(\%)$ \\
\hline \multirow[t]{2}{*}{ Gender } & Male & $37(10.9)$ \\
\hline & Female & $\begin{array}{l}300(88.2) \text { [3 respondents refused to state } \\
\text { this] }\end{array}$ \\
\hline \multirow[t]{3}{*}{ Age } & $18-35$ & $113(33.2)$ \\
\hline & $36-55$ & $177\left(5^{2.1}\right)$ \\
\hline & $5^{6^{+}}$ & $45(13.2)$ [ 5 respondents refused to state this] \\
\hline \multirow[t]{2}{*}{ Nature of Work } & Paid & $100(29.4)$ \\
\hline & Voluntary & $238(70)$ [2 respondents refused to state this] \\
\hline \multirow[t]{2}{*}{ Nature of Role } & Single & $83(24.4)$ \\
\hline & Multiple & $255(75)$ [2 respondents refused to state this] \\
\hline \multirow[t]{2}{*}{ Care In Home } & Yes & $221(65)$ \\
\hline & No & $\begin{array}{l}116(34.1) \text { [3 respondents refused to state } \\
\text { this] }\end{array}$ \\
\hline \multirow{3}{*}{$\begin{array}{l}\text { Exposure to } \\
\text { Euthanasia }\end{array}$} & Yes & $192(56.5)$ \\
\hline & & \\
\hline & No & $147(43.2)[1$ respondent refused to state this] \\
\hline
\end{tabular}

TABLE 2 Zero-point pearson and partial order bivariate correlations for ProQOL subscales $(N=340)$

\section{$r$ and [partial $r$ ]}

ProQOL subscale

Burnout

Secondary traumatic stress

Compassion Satisfaction

$-.503^{*}\left[-.431^{*}\right]^{\mathrm{b}}$

$-.291 *[.052(\text { n.s. })]^{\mathrm{a}}$

Burnout

$.647^{*}\left[.605^{*}\right]^{\mathrm{c}}$

Secondary Traumatic

Stress

* Correlation is significant at the .05 level (2-tailed).

a Partial order correlation controlling for Burnout.

b Partial order correlation controlling for Secondary Traumatic Stress.

c Partial order correlation controlling for Compassion Satisfaction. 


\section{ProQOL Score Differences Across Sociodemographic/Work Variables} Several Mann-Whitney $U$ tests were conducted to assess potential group differences on the ProQOL subscale groups (low, average, and high) across the sociodemographic and work variables. This test statistic was chosen because of the uneven sample distribution across five of the six variables and the ordinal nature of the measures. Table 3 highlights the significant $(p<.05)$ differences. Women scored significantly higher on secondary traumatic stress than men, and so did those who were involved in multiple roles within animal rescue operations versus those involved in only single roles. Lastly, participants involved in multiple roles scored significantly higher on burnout than did those involved in only single roles.

\section{Associations in ProQOL Subscales Across Sociodemographic/ Work Variables}

Several Pearson $\chi^{2}$ tests were conducted to identify any associations in participants' scores on each of the three subscales based on the six dichotomous sociodemographic and work variables. To perform the $\chi^{2}$ analysis and followup logistic regression analyses, the sample was divided into low, average, and high scores for each of the subscales, according to the manual (Stamm, 2010). Table 4 illustrates the significant differences among respondents' ProQOL subscale scores and the sociodemographic and work variables.

Burnout was the most frequently occurring subscale to emerge, with three significant differences within the sociodemographic and work-related variables followed by three significant secondary-traumatic stress differences

TABLE 3 Significant Mann-Whitney $U$ test group differences across ProQOL subscales

\begin{tabular}{|c|c|c|c|}
\hline ProQOL Subscale & Variable $(n)$ & Mean Rank & Mann-Whitney $U$ \\
\hline & Gender (3०9) & & \\
\hline \multirow[t]{3}{*}{ Secondary Traumatic Stress } & Male (33) & 117.02 & $3300.5^{*}$ \\
\hline & Female $(276)$ & $159 \cdot 54$ & \\
\hline & Role $(311)$ & & \\
\hline \multirow[t]{3}{*}{ Secondary Traumatic Stress } & Single $(78)$ & 127.4 & $6856.5^{*}$ \\
\hline & Multiple (233) & $165 \cdot 57$ & \\
\hline & Role $\left(33^{8}\right)$ & & \\
\hline \multirow[t]{2}{*}{ Burnout } & Single (83) & 144.68 & $8522.5^{*}$ \\
\hline & Multiple (255) & $177 \cdot 5^{8}$ & \\
\hline
\end{tabular}

${ }^{*} p<.05$. 
TABLE 4 Significant differences among ProQOL subscale scores and sociodemographic/ work variables

\begin{tabular}{|c|c|c|c|}
\hline $\begin{array}{l}\text { Pearson } \\
\chi^{2}(d f)\end{array}$ & $N$ & Relationship & $\begin{array}{l}\text { Direction and interpretation of } \\
\text { relationship }\end{array}$ \\
\hline $7.05^{*}(2)$ & $33^{8}$ & $\begin{array}{l}\text { Compassion satisfac- } \\
\text { tion } \times \text { single } / \text { multiple } \\
\text { role }(s)\end{array}$ & $\begin{array}{l}\text { Those performing multiple roles received } \\
\text { higher compassion satisfaction scores } \\
\text { than those who performed single roles. }\end{array}$ \\
\hline $8.99^{*}(2)$ & $33^{8}$ & $\begin{array}{l}\text { Burnout } \times \text { single } / \\
\text { multiple role }(\mathrm{s})\end{array}$ & $\begin{array}{l}\text { Those performing multiple roles scored } \\
\text { significantly higher on burnout than } \\
\text { those who performed single roles. }\end{array}$ \\
\hline $6.8^{*}(2)$ & 337 & $\begin{array}{l}\text { Burnout } \times \text { care } \\
\text { in-home }\end{array}$ & $\begin{array}{l}\text { Those who cared for animals in their } \\
\text { homes scored significantly higher on } \\
\text { burnout than those who did not care for } \\
\text { animals in their homes. }\end{array}$ \\
\hline $13.6 *(2)$ & 339 & $\begin{array}{l}\text { Burnout } \times \text { euthanasia } \\
\text { exposure }\end{array}$ & $\begin{array}{l}\text { Those who were exposed to euthana- } \\
\text { sia were more likely to suffer burnout } \\
\text { than those who were never exposed to } \\
\text { euthanasia. }\end{array}$ \\
\hline $11 *(2)$ & 309 & $\begin{array}{l}\text { Secondary traumatic } \\
\text { stress } \times \text { gender }\end{array}$ & $\begin{array}{l}\text { Females reported higher levels of second- } \\
\text { ary traumatic stress than males. }\end{array}$ \\
\hline $12.5^{*}(2)$ & 311 & $\begin{array}{l}\text { Secondary traumatic } \\
\text { stress } \times \text { single } / \\
\text { multiple role }(\mathrm{s})\end{array}$ & $\begin{array}{l}\text { Those in multiple roles experienced } \\
\text { significantly higher levels of secondary } \\
\text { traumatic stress when compared to those } \\
\text { who were engaged in only one role. }\end{array}$ \\
\hline $10.65^{*}(2)$ & 309 & $\begin{array}{l}\text { Secondary traumatic } \\
\text { stress } \times \text { care in home }\end{array}$ & $\begin{array}{l}\text { Those who cared for animals in the home } \\
\text { were more likely to suffer from secondary } \\
\text { traumatic stress when compared to those } \\
\text { who did not care for animals in the home. }\end{array}$ \\
\hline
\end{tabular}

${ }^{*} p<.05$.

and one significant compassion fatigue difference. The nature of the worklooking after single or multiple animals — was the most frequently occurring work-related role to be significantly associated with the three subscales, followed by caring for animals in the home, gender, and exposure to euthanasia.

To tease apart the impacts that sociodemographic and work variables have on the three ProQOL subscales, a series of binary logistic regression models were tested on the already significant findings from the aforementioned 
contingency analyses. Binary logistic regression was chosen because the outcome variables are dichotomously scored and the ProQOL subscales were ordinal in nature. Results from each subscale and significant sociodemographic and work variables are summarized. Tables 5 and 6 include the binary logistic regression coefficients; Wald statistics; and the estimated change in odds, along with a $95 \% \mathrm{CI}$ for each analysis.

\section{Compassion Satisfaction}

The outcome variable "role" was coded $o=\operatorname{single}$ and $1=$ multiple. A test of the full model (compassion satisfaction) compared with a constant-only model was statistically significant, $\chi^{2}(2)=6.85, p<.05$. The strength of association between compassion satisfaction and having multiple roles was weak, with Cox and Snell's $R^{2}=0.02$ and Nagelkerke's $R^{2}=0.03$. Respondents with average levels of compassion satisfaction (i.e., higher levels of compassion satisfaction

TABLE 5 Compassion satisfaction, burnout, and sociodemographic/work variables

\begin{tabular}{rllllll}
\hline $\operatorname{Rank}_{0}$ order $^{\wedge}$ & $B$ & $S E$ & Wald $\quad d f$ & Significance $\operatorname{Exp}(B)$ & $\begin{array}{l}95 \% \mathrm{CI} \\
\text { (Lower) }\end{array}$ & $\begin{array}{l}95 \% \mathrm{CI} \\
\text { (Upper) }\end{array}$
\end{tabular}

Compassion satisfaction (cs) and nature of role

cs (low)

$\begin{array}{lll}6.902 \quad 2 & .032\end{array}$

cs (average)

$.805 \quad .308$

6.8231 .009*

cs (high)

$.509 \quad .322$

$\begin{array}{lll}2.500 \quad & 1 & .114\end{array}$

$2.237 \quad 1.223$

4.092

$\begin{array}{ll}1.663 & 0.885\end{array}$

3.125

Burnout (Bо) and exposure to euthanasia

Bo (low)

BO (average)

13.216

во (high)

$.369 \quad .265$

$\begin{array}{lll}1.933 \quad 1 & 164\end{array}$

$1.446 \quad .86$ o

2.434

Burnout (BO) and nature of role

Bo (low)

$12.832 \quad 1 \quad .00{ }^{*}$

$2.992 \quad 1.643$

$5 \cdot 451$

Bo (average)

$.651 \quad .293$

во (high)

$.951 \quad .344$

$\begin{array}{lll}8.752 & 2 & .013 \\ 4.923 & 1 & .026^{*} \\ 7.645 & 1 & .006^{*}\end{array}$

$1.917 \quad 1.079$

3.405

$\begin{array}{lll}2.588 & 1.319 & 5.079\end{array}$

Burnout (во) and care in the home

Bо (low)

во (average)

$\begin{array}{rr}.485 & .273 \\ .786 & .311\end{array}$

$\begin{array}{lll}6.699 \quad 2 & .035\end{array}$

во (high)

.311

$\begin{array}{lll}3.15^{8} \quad 1 & .076\end{array}$

$6.404 \quad 1.011 *$

$\begin{array}{ll}1.624 & .951 \\ 2.195 & 1.194\end{array}$

2.773

4.036

$\wedge$ Reference category is the lowest rank-ordered group in each instance.

* Statistically significant. 


\begin{tabular}{lllllll}
\hline Rank order^ & $B$ & $S E$ & Wald $\quad d f$ & Significance $\operatorname{Exp}(B)$ & $\begin{array}{l}95 \% \mathrm{CI} \\
\text { (Lower) }\end{array}$ & $\begin{array}{l}95 \% \mathrm{CI} \\
\text { (Upper) }\end{array}$ \\
\hline
\end{tabular}

Secondary traumatic stress (sTs) and gender

\begin{tabular}{|c|c|c|c|c|c|c|c|c|}
\hline sts (low) & & & 10.128 & 2 & $.006^{*}$ & & & \\
\hline sts (average) & 1.154 & .421 & $7 \cdot 512$ & 1 & $.006^{*}$ & 3.171 & 1.389 & 7.239 \\
\hline sTs (high) & 1.277 & .508 & 6.323 & 1 & $.012 *$ & $3 \cdot 585$ & 1.325 & 9.696 \\
\hline
\end{tabular}

Secondary traumatic stress (sTS) and nature of role

\begin{tabular}{|c|c|c|c|c|c|c|c|c|}
\hline sts (low) & & & 11.737 & 2 & $.003^{*}$ & & & \\
\hline sts (average) & .420 & .301 & 1.944 & 1 & .163 & $1.5^{22}$ & .843 & 2.747 \\
\hline sts (high) & 1.366 & .400 & 11.692 & 1 & $.001^{*}$ & 3.920 & 1.792 & 8.577 \\
\hline
\end{tabular}

Secondary traumatic stress (sts) and care in the home sTs (low)

\begin{tabular}{lrrrrr} 
STS (average) & .584 & .288 & 4.112 & 1 & $.043^{*}$ \\
STS (high) & 1.082 & .338 & 10.222 & 1 & $.001 *$ \\
\hline$\wedge$ & Reference category is the lowest rank-ordered group in each instance. \\
$*$ & Statistically significant.
\end{tabular}

than those with low scores) were over twice as likely to play multiple roles in caring for animals as respondents who performed a single role.

\section{Burnout}

The outcome variable "exposed to euthanasia" was coded $\mathrm{o}=$ no and $1=$ yes. A test of the full model (burnout) compared with a constant-only model was statistically significant, $\chi^{2}(2)=13.904, p<.05$. The strength of association between burnout and being exposed to euthanasia was weak, with Cox and Snell's $R^{2}=0.04$ and Nagelkerke's $R^{2}=0.054$. Respondents who experienced high levels burnout were almost three times as likely to have been exposed to euthanasia in comparison to those who were not exposed to euthanasia.

The outcome variable "role" was coded $\mathrm{o}=$ single and $1=$ multiple. A test of the full model (burnout) compared with a constant-only model was statistically significant, $\chi^{2}(2)=8.723, p<.05$. The strength of association between burnout and having multiple roles was weak with Cox and Snell's $R^{2}=0.025$ and Nagelkerke's $R^{2}=0.038$. Respondents engaged in multiple roles were twoand-a-half times more likely to suffer from high levels of burnout than those engaged in only one role. 
The outcome variable "care in the home" was coded $o=$ no and $1=$ yes. A test of the full model (burnout) compared with a constant-only model was statistically significant, $\chi^{2}(2)=6.75, p<.05$. The strength of association between compassion satisfaction and having multiple roles was weak with Cox and Snell's $R^{2}=0.02$ and Nagelkerke's $R^{2}=0.027$. Respondents who had cared for animals at home were twice as likely to suffer higher levels of burnout as those who did not care for animals at home.

\section{Secondary Traumatic Stress}

The outcome variable "gender" was coded $o=$ male and $1=$ female. A test of the full model (secondary traumatic stress) compared with a constant-only model was statistically significant, $\chi^{2}(2)=9.75, p<.05$. The strength of association between compassion satisfaction and having multiple roles was weak with Cox and Snell's $R^{2}=0.031$ and Nagelkerke's $R^{2}=0.063$. Table 6 summarizes the raw binary logistic regression coefficients, Wald statistics, and the estimated change in odds of having multiple roles versus a single role, along with a $95 \%$ CI. Female respondents were three-and-a-half times as likely to suffer higher levels of secondary traumatic stress as males.

The outcome variable "role" was coded $o=$ single and $1=$ multiple. A test of the full model (secondary traumatic stress) compared with a constant-only model was statistically significant, $\chi^{2}(2)=13.32, p<.05$. The strength of association between compassion satisfaction and having multiple roles was weak with Cox and Snell's $R^{2}=0.042$ and Nagelkerke's $R^{2}=0.062$. Respondents in multiple roles were almost four times more likely than those in single roles to experience higher levels of secondary traumatic stress.

The outcome variable "care in the home" was coded $o=$ yes and $1=$ no. A test of the full model (secondary traumatic stress) compared with a constantonly model was statistically significant, $\chi^{2}(2)=10.668, p<.05$. The strength of association between compassion satisfaction and having multiple roles was weak with Cox and Snell's $R^{2}=0.034$ and Nagelkerke's $R^{2}=0.047$. Respondents who cared for animals in the home were almost three times more likely than those who did not care for animals in the home to experience higher levels of secondary traumatic stress.

\section{Discussion}

The results from the correlation analyses revealed a positive correlation between burnout and secondary traumatic stress. Thus, as burnout scores increased, 
secondary traumatic stress scores also tended to increase. In addition, a negative correlation was found between both compassion satisfaction and burnout, as well as between compassion satisfaction and secondary traumatic stress; as burnout and secondary traumatic stress scores increased, compassion satisfaction scores decreased. The correlations remained significantly associated when each scale was statistically controlled.

These findings correspond with a number of studies on professional quality of life in a number of different populations. Secondary traumatic stress was found to be negatively correlated with compassion satisfaction in a sample of hospice palliative care workers (Slocum-Gori et al., 2013). An earlier study on hospice staff produced similar findings with a strong negative correlation between compassion satisfaction and burnout and a negative correlation between compassion satisfaction and secondary traumatic stress (Alkema, Linton, \& Davies, 2008). A strong correlation was also found between compassion satisfaction and secondary traumatic stress in members of a U.S. crisis response team (Corey-Souza \& Capella, 2007). The correlational findings of the present study cohere with the findings of a number of other studies in caregiving population samples.

Additionally, the negative correlation found between compassion satisfaction and both burnout and secondary traumatic stress may be indicative of a possible mitigating role for compassion satisfaction and the negative effects of animal rescue work. However, it could also be that burnout and secondary trauma undermine compassion satisfaction. It cannot be stated with certainty that either of these interpretations is correct, as the study is crosssectional in nature. These results do, however, accord with Figley's (1995) findings regarding the negative association between compassion satisfaction and burnout as well as secondary traumatic stress.

\section{Gender Differences}

Regarding gender differences, females scored significantly higher on secondary traumatic stress than did males. Female respondents were three-and-a-half times as likely to suffer higher levels of secondary traumatic stress as males. Males were less likely than females to score average or high on secondary traumatic stress. Studies have shown that females are more likely to report secondary traumatic symptoms than male participants (Horesh et al., 2015). Despite the uneven gender balance in the data, the ratio is reflective of current animal-care worker trends where females now dominate this employment sector (Markovits \& Queen, 2009). 


\section{Nature of Role}

Animal rescue workers who were involved in multiple caring roles within animal rescue operations scored significantly higher on secondary traumatic stress and burnout when compared to those involved in only single roles, but they also had higher levels of compassion satisfaction than respondents who served in one role only. There is very little information regarding the effects of multiple roles on levels of compassion satisfaction. However, a previous study involving therapists and compassion satisfaction found that the amount of work hours partially accounted for variance in compassion satisfaction scores (Killian, 2008). Consequently, it is probable that those engaging in a single role may spend fewer hours working in animal rescue than those engaging in multiple roles, thus yielding similar results to those of Killian's work on therapists.

Respondents who had multiple caring roles were more likely to suffer burnout than those who performed only one role, and they were two-and-a-half times more likely to suffer from high levels of burnout than those engaged in only one role. They were also almost four times more likely than those in single roles to experience higher levels of secondary traumatic stress. Having multiple caring roles as well as caring for rescue animals in the home may closely reflect the variables from previous research such as high work demand, hours of overtime, and work overload, which in turn may explain the similarities between the findings of this study and others based on different populations.

Outar and Rose (2017) demonstrated a significant relationship between work demands and staff burnout among direct care staff. Similarly, hours of overtime were found to be predictive of burnout in psychological wellbeing practitioners (Westwood et al., 2017), with work overload found to be predictive of burnout in a sample of general employees (de Beer et al., 2016). It is possible that the specific variables used in this study - having multiple roles and caring for rescue animals in the home-may reflect the variables high work demand, hours of overtime, and work overload used in other studies, which explains why the present study produced similar results.

\section{Euthanasia}

One of the most significant results of this research study was in relation to animal rescue workers who were exposed to the euthanasia of animals. Animal rescue workers who were exposed to the euthanasia of animals were almost three times more likely to score high on burnout than those who were not exposed to euthanasia. In the cases of the limited literature available on animal rescue workers, euthanasia appears to be a core focus. Euthanasia-related 
strain has been found to be prevalent among animal shelter euthanasia technicians, producing some similar symptoms to burnout (Reeve et al., 2005). Furthermore, euthanasia has been identified as a source of occupational stress for veterinarians (Sanders, 1995; Schneider, 1996).

Many veterinarians experience severe emotional ambivalence when faced with the responsibility of euthanizing an animal whom they have come to share a bond with. Thus, it is probable that animal rescue workers may share the same experience. Animal rescue workers may experience guilt and frustration as a result of their responsibility to euthanize unwanted animals, perhaps in turn causing them to become more susceptible to burnout, as displayed in the results of the present study.

\section{In-Home Fostering}

Respondents who had cared for animals at home were twice as likely to suffer higher levels of burnout as those who did not care for animals at home. A causal relationship cannot be established, as the data were not analyzed longitudinally and there is no measure of causality. At most, it can be stated that there does appear to be significant relationships between the constructs measured, but the direction of these relationships cannot be deduced with the current data. Respondents who cared for animals in the home were almost three times more likely than those who did not care for animals in the home to experience higher levels of secondary traumatic stress. Schneider and Roberts (2016) state that animal care workers in their study mentioned feeling pressured to bring rescue animals home on account of overload at work.

A number of earlier studies have shown that exposure to traumatized individuals is a predictive factor of secondary traumatic stress symptoms. A study on alcohol and drug workers in Australia revealed that a higher traumatized client workload was an individually predictive factor of prevalence of secondary traumatic stress (Ewer et al., 2015). In addition, a study on trainee psychologists found that the total number of hours providing trauma-focused therapy to severely traumatized individuals was a significant predictor of secondary traumatic stress (Gottesman, 2008). Individuals who provide foster care for rescue animals in their own homes are often responsible for caring for animals who are deeply traumatized and/or injured.

These animals are often unable to cope in a shelter environment, thus requiring many hours of care and rehabilitation in a home environment in order for them to be deemed suitable for rehoming or return to the wild. Hence, it may be possible that an animal rescue worker's constant exposure to such deeply traumatized animals may result in secondary traumatic stress symptoms, the 
same way alcohol/drug workers and psychologists experience secondary traumatic stress as a result of their time spent with traumatized clients.

\section{Implications}

Our findings are important when identifying how animal rescue workers may potentially suffer from the work they do, and how particular aspects of animal rescue work may increase or decrease an individual's risk. These findings can prove invaluable to animal rescue and welfare organizations, allowing them to provide more specific supports to staff and volunteers who may be most vulnerable based on the specifics of their animal rescue work. For example, those who provide foster care for rescue animals in their homes could have rotatory break periods in an attempt to lower their risk of secondary traumatic stress. While this suggestion may not be entirely feasible for many organizations due to the never-ending influx of abused and neglected animals with nowhere to go, it may still prove useful to both the organization and the individual to be aware of the possible increased risk, and to be on the lookout for aforementioned symptoms and ways to reduce them.

\section{Conclusion}

The cross-sectional nature of the study does not allow for any longitudinal analyses to be conducted despite an indication of resilience among respondents who take on multiple roles-caring for multiple animals was associated with increased compassion satisfaction. Also, the conclusions drawn from the data are limited to associational relations, so no causal relationships can be established due to the cross-sectional design of the study. For example, it cannot be concluded that burnout results in animal care workers taking animals home and caring for them there nor can it be concluded that the reverse is true. It can only be concluded that a significant association exists between the various measures of professional quality of life and various aspects of the job.

In the future, longitudinal data can be collected from animal care workers and a causal link can be established between the nature of the job and various quality-of-life measures. A further limitation was the lower number of males responding to the survey, but uneven sample sizes is not a major concern, as rank-ordered analyses were used for the data. However, the animal-care worker population is female-dominated, and as such, the sample used in this study is thus reflective of the larger population in terms of the gender ratio. 
Stamm (2010) discusses how the ProQOL measure is best used in its continuous form. A number of the analyses conducted in present study utilized cut scores for the ProQOL. However, while cut scores are provided in the ProQOL manual, they are described as "potentially over inclusive." Furthermore, the ProQOL is a self-report measure, meaning the data collected for the present study may have been affected by response bias or a respondent's introspective ability. Future researchers may opt to focus on a more refined population of animal rescue workers based on the results of this study, and perhaps gather richer data by utilizing in-depth interviewing in the same vein as the study conducted by Schneider and Roberts (2016).

Due to this study's significant finding that those engaging in euthanasia practices were almost three times more likely to score high on burnout than those uninvolved in euthanasia, it may be useful for future research to focus on the effects the euthanasia of animals has on animal rescue workers, while perhaps simultaneously identifying a particularly vulnerable subgroup of the population.

Additionally, the specific population of animal rescue workers who provide foster care for rescue animals in their own homes-who constituted a considerable $65 \%$ of the current sample — may also be identified as a particularly vulnerable subgroup by future researchers due to their likelihood to score high on secondary traumatic stress based on this study. The significant differences between animal rescue workers who engaged in multiple roles in animal rescue - a majority of $75 \%$ of the current sample - and those who engaged in a single role may be of interest to future researchers due to the high levels of reported burnout and secondary traumatic stress.

Furthermore, a qualitative research design may be useful in understanding the lived experiences of animal rescue workers. Where interviews are not limited to specific questions, issues and subjects which may be alluded to by animal rescue workers can be explored and evaluated in far more detail. Future qualitative researchers may wish to loosely structure interviews and/or focus groups based around findings revealed in the present quantitative study.

Burnout and secondary traumatic stress are serious issues causing a number of unfavorable physical, emotional, behavioral, and cognitive symptoms. As well as having an effect on the performance of an animal rescue worker, these issues can negatively affect the emotional wellbeing of individuals and their relationships with those closest to them. If the symptoms of burnout and secondary traumatic stress are not recognized and acknowledged, the long-term effects may thwart the fundamental calling of an animal rescue worker-to care for and help abused and neglected animals. Further and more in-depth 
research is required in order to provide a more distinct understanding of the effects working in animal rescue has on individuals. It is hoped that the results of the present study, and further studies, will build a framework of literature based on this vulnerable and under-researched population, inevitably providing support and advice for those who may so deeply need it.

In sum, animal rescue workers performing multiple roles received higher compassion satisfaction scores than those who performed single roles, but they also scored significantly higher on burnout and secondary traumatic stress than those who performed single roles. So, while there is a measure of resilience evident in animal rescue workers who care for multiple animals, this workload and emotionally taxing nature of the work resulted in higher burnout and secondary traumatic stress. This indicates that animal rescue workers can take on heavier workloads but would need support systems in place to help deal with the negative effects of this work. Female rescue workers also reported higher levels of secondary traumatic stress than males. Those who cared for animals in their homes scored significantly higher on burnout and secondary traumatic stress than those who did not care for animals in their homes. Support systems are needed for those workers taking in foster animals in their own homes.

Those who were exposed to euthanasia were more likely to suffer burnout than those who were not. Once again, support systems around the experience of euthanasia need to be put in place if rescue workers are to experience better levels of professional quality of life in their invaluable work. After all, over twice as many animal rescue workers in our sample work in a voluntary capacity and should be compensated for the emotionally draining work with which they engage.

\section{References}

Aguilera, D. C. (1995). Crisis intervention: Theory and methodology. St. Louis: Mosby.

Alkema, K., Linton, J. M., \& Davies, R. (2008). A study of the relationship between selfcare, compassion satisfaction, compassion fatigue, and burnout among hospice professionals. Journal of Social Work in End-of-Life and Palliative Care, 4(2), 101-119.

Arluke, A. (1991). Coping with euthanasia: A case study of shelter culture. Journal of the American Veterinary Medical Association, 198(7), 1176.

Arluke, A., \& Sanders, C. (1996). Regarding animals. Philadelphia: Temple University Press.

Baran, B. E., Allen, J. A., Rogelberg, S. G., Spitzmüller, C., DiGiacomo, N. A., Webb, J. B., ... \& Walker, A. G. (2009). Euthanasia-related strain and coping strategies in animal 
shelter employees. Journal of the American Veterinary Medical Association, 235(1), $83-88$.

Barnes, M. F. (2005). When a child is traumatized or physically injured: The secondary trauma of parents. In D. R. Catherall (Ed.), Specific stressors: Interventions with couples and families (pp. 73-9o). New York: Brunner-Routledge.

Barr, P. (2017). Compassion fatigue and compassion satisfaction in neonatal intensive care unit nurses: Relationships with work stress and perceived social support. Traumatology, 23(2), 214-222.

Cherniss, C. (1980). Staff burnout job stress in the human services. New York: Praeger.

Conrad, D., \& Kellar-Guenther, Y. (2006). Compassion fatigue, burnout, and compassion satisfaction among Colorado child protection workers. Child Abuse and Neglect, 3०(10), 1071-1080.

Corey-Souza, P. A. (2007). Compassion fatigue in members of the Florida crisis response team: A consequence of caring. Minnesota: Capella University.

De Beer, L. T., Pienaar, J., \& Rothmann, J. R. S. (2016). Work overload, burnout, and psychological ill-health symptoms: A three-wave mediation model of the employee health impairment process. Anxiety, Stress, and Coping, 29(4), 387-399.

Ewer, P. L., Teesson, M., Sannibale, C., Roche, A., \& Mills, K. L. (2015). The prevalence and correlates of secondary traumatic stress among alcohol and other drug workers in Australia. Drug and Alcohol Review, 34(3), 252-258.

Farber, B. A. (1983). Stress and burnout in the human service professions. New York: Pergamon Press.

Figley, C. R. (1995). Compassion fatigue as secondary traumatic stress disorder: An overview. In C. R. Figley (Ed.), Compassion fatigue (pp. 1-20). New York: Brunner Mazel.

Figley, C. R., \& Roop, R. G. (2006). Compassion fatigue in the animal-care community. Washington, DC: Humane Society Press.

Frommer, S. S., \& Arluke, A. (1999). Loving them to death: Blame-displacing strategies of animal shelter workers and surrenderers. Society \& Animals, 7(1), 1-16.

Gottesman, J. (2008). Secondary traumatic stress and resilience among practicum-level psychology trainees. The University of the Rockies.

Horesh, D., Lowe, S. R., Galea, S., Uddin, M., \& Koenen, K. C. (2015). Gender differences in the long-term associations between post-traumatic stress disorder and depression symptoms: Findings from the Detroit neighborhood health study. Depression and Anxiety, 32(1), 38-48.

Killian, K. D. (2008). Helping till it hurts? A multimethod study of compassion fatigue, burnout, and self-care in clinicians working with trauma survivors. Traumatology, $14(2), 32-44$.

Lauvrud, C., Nonstad, K., \& Palmstierna, T. (2009). Occurrence of post-traumatic stress symptoms and their relationship to professional quality of life (ProQOL) in nursing 
staff at a forensic psychiatric security unit: A cross-sectional study. Health and Quality of Life Outcomes, 16(7), 17-31.

Leiter, M., \& Schaufeli, W. (1996). Consistency of the burnout construct across occupations. Anxiety, Stress and Coping, 9, 229-243.

Luster, R., J. (2005). An analysis of the effects of vicarious trauma as measured by the ProQOLR III test dissertation Capella University. Retrieved from http://wwwlib.umi .com/dissertations/fullcit/3162618.

Markovits, A. S., \& Queen, R. (2009). Women and the world of dog rescue: A case study of the state of Michigan. Society \& Animals, 17, 325-342.

Maslach, C., \& Jackson, S. (1986). Maslach burnout inventory manual (2nd ed.). Palo Alto: Consulting Psychologists Press.

NiCarthy, G., Merriam, K., \& Coffernan, S. (1984). Talking it out: A guide to groups for abused women. Seattle: Seal Press.

Outar, C., \& Rose, J. (2017). Is there a relationship between role identity, work demands, and burnout in direct care staff working with individuals with intellectual disability? Journal of Intellectual and Developmental Disability, 42(2), 123-130.

Prosser, D., Johnson, S., Kuipers, E., Szmukler, G., Bebbington, P., \& Thornicroft, G. (1996). Mental health, burnout and job satisfaction among hospital and communitybased mental health staff. British Journal of Psychiatry, 169, 334-337.

Rank, M. G., Zaparanick, T. L., \& Gentry, J. E. (2009). Animal care compassion fatigue. Best Practices in Mental Health, 5(2), 40-61.

Reeve, C. L., Rogelberg, S. G., Spitzmüller, C., \& DiGiacomo, N. (2005). The caringkilling paradox: Euthanasia related strain among animal-shelter workers. Journal of Applied Social Psychology, 35, 119-143.

Sanders, C. R. (1995). Killing with kindness: Veterinary euthanasia and the social construction of personhood. Sociological Forum, 10(2), 195-214.

Schneider, B. J. (1996). Euthanasia and the veterinarian. The Canadian Veterinary Journal, 37(4), 217.

Schneider, M., \& Roberts, J. (2016). Shelter specific stress among employees in animal shelters. Human-Animal Interaction Bulletin, 4(1), 19-38.

Simon, C. E., Pryce, J. G., Roff, L. L., \& Klemmack, D. (2006). Secondary traumatic stress and oncology social work: Protecting compassion from fatigue and compromising the worker's worldview. Journal of Psychosocial Oncology, 23(4), 1-14.

Slocum-Gori, S., Hemsworth, D., Chan, W. W., Carson, A., \& Kazanjian, A. (2013). Understanding compassion satisfaction, compassion fatigue and burnout: A survey of the hospice palliative care workforce. Palliative Medicine, 27(2), 172-178.

Stamm, B. H. (2002). Measuring compassion satisfaction as well as fatigue: Developmental history of the compassion satisfaction and fatigue test. In C. R. Figley (Ed.), Treating compassion fatigue (pp. 107-119). New York: Brunner-Routledge. 
Stamm, B. H. (2010). The concise ProQOL manual (2nd ed.). Pocatello, ID. Retrieved from www.ProQOL.org.

Tiplady, C. (2013). Animal abuse: Helping animals and people. CABI: Wallingford, Oxfordshire.

Westwood, S., Morison, L., Allt, J., \& Holmes, N. (2017). Predictors of emotional exhaustion, disengagement and burnout among improving access to psychological therapies (IAPT) practitioners. Journal of Mental Health, 26(2), 1-8. 